\title{
Ten years after the Dutch public health campaign on folic acid: the continuing challenge
}

\author{
Hermien E. K. de Walle • \\ Lolkje T. W. de Jong-van den Berg
}

Received: 25 October 2007 / Accepted: 10 December 2007 /Published online: 22 January 2008

(C) The Author(s) 2008

\begin{abstract}
Background Folic acid use in the periconceptional period reduces the risk of neural tube defects (NTDs). However, applying this knowledge in daily practice is not an easy task. We report here the current level of folic acid use in the Netherlands and discuss the figures within the framework of a national governmental campaign held in 1995 promoting the use of folic acid and the professional interventions undertaken since then.

Methods We carried out six studies in the northern Netherlands during 1995, 1996, 1998, 2000, 2003 and 2005, respectively. The same methodology in the same health professionals' practices was followed in all studies. Pregnant women attending their first or second antenatal visit were asked to fill in a questionnaire aimed at assessing their awareness and use of folic acid.

Results In 2005, most of the pregnant women used folic acid "at some time in their pregnancy", and 51\% used it for the entire advised period. Prior knowledge on the protective affect of folic acid and on the period of use was strongly related to the level of education. The use of folic acid in a previous pregnancy [odds ratio (OR) 3.9, 95\% confidence interval $(95 \% \mathrm{CI}) 1.6-9.9]$, the use of an oral contraceptive (OR 2.1, 95\% CI 1.1-4.1) and parity (OR 0.08, 95\% CI $0.01-0.5)$ significantly predicted the current correct use.
\end{abstract}

H. E. K. de Walle $(\bowtie)$

Department of Medical Genetics,

University Medical Centre Groningen, University of Groningen,

Postbus 30001, 9700 RB Groningen, The Netherlands

e-mail: h.e.k.de.walle@medgen.umcg.nl

L. T. W. de Jong-van den Berg

Department of Social Pharmacy,

Pharmacoepidemiology and Pharmacotherapy,

Groningen University Institute of Drug Exploration,

Groningen, The Netherlands
The most recent figures revealed that there is still a large gap between more highly and less educated women in terms of taking folic acid in the advised period: 63 versus $31 \%$, respectively.

Discussion The aim of the Dutch Ministry of Health is to have $70 \%$ of Dutch women wanting to become pregnant use folic acid supplements in the advised period by 2010 . While this level has almost been reached among more highly educated women (63\%), it will take a great deal more effort, money and creativity to achieve the necessary increase from the current level of $31 \%$ among women with a lower educational background.

Keywords Folic acid use - Information ·

Oral contraceptives · Pregnancy · Supplementation

\section{Background}

An increased intake of folic acid in the periconceptional period reduces the risk of neural tube defects (NTDs) by at least $50 \%$ [1]. There are two standard strategies to achieve periconceptional intake of folic acid: fortification of staple foods with folic acid and/or health education initiatives aimed at increasing the awareness of the target population to the importance of taking folic acid supplements. However, recent studies have shown that translating this knowledge into prevention is not easy $[2,3]$. The current recommendation of taking $400 \mu \mathrm{g}$ of folic acid periconceptionally has been found not to be the optimal approach, and although the prevalence of NTDs has now declined substantially in the northern part of the Netherlands, it has remained at about the same level across Europe in general. The results of these studies clearly suggest that only a public health policy that includes folic acid fortification of 
staple foods is likely to result in the large-scale prevention of NTDs. Since, in the short term, many European countries are not expected to adopt such a fortification policy, alternative strategies encouraging the taking of supplements need to be developed and implemented.

We report here the latest figures on the use of folic acid in the Netherlands. The situation in the Netherlands is interesting because of the high percentage of planned pregnancies - close to $80 \%$ of all pregnancies - and staple foods are not fortified with folic acid. The aim of the Ministry of Health is to have $70 \%$ of women use folic acid supplements in the periconceptional period by 2010. A government-sponsored mass media campaign was held in 1995 to promote the use of folic acid supplements by women planning a pregnancy. Data from the northern part of the Netherlands show that after this campaign there was a $43 \%$ [ $95 \%$ confidence interval $(95 \%$ CI) $15-61 \%$ ] reduction in the total prevalence of NTDs (from 11.44 per 10,000 births in $1989-1991$ to 6.52 per 10,000 in 2000 2002) [4]. In addition, since 2004, Dutch pharmacies have been carrying out an ongoing proactive intervention aimed at informing and motivating women using oral contraceptives to start taking folic acid supplements "before conception". A pilot study showed that women who were given this information by their pharmacy used folic acid significantly more often than those who were not given any information. Among women planning their first pregnancy folic acid use was $62.5 \%$ in the intervention group versus $30.8 \%$ in the reference group [5].

We describe here what has happened to folic acid intake in the Netherlands since the national campaign in 1995 and the professional interventions undertaken since then.

\section{Methods and subjects}

We carried out six studies in northern Netherlands during 1995, 1996, 1998, 2000, 2003 and 2005, respectively [6-8]. The same methodology in the same health professionals' practices was followed in all studies. The obstetric departments of three hospitals and seven midwives' practices participated in all of the surveys. Pregnant women attending their first or second antenatal visit were asked to fill in a questionnaire. Responses to our surveys varied between $75-90 \%$ and there was no temporal trend.

The questionnaire covered the awareness of the respondents to the use of folic acid and current use (open-ended questions for measuring qualitative knowledge) and demographics. In previous surveys, one of our focal points was educational level since this was found to be an important predictor of compliance with the advised use of folic acid. The highest completed level of education was taken as an indicator of socio-economic status (SES). In total there were seven levels of education, ranging from elementary school to university. For statistical analysis, the levels were merged into low (levels 1-3), middle (4-5) and high (6-7) education. The methodology has been described elsewhere $[9,10]$. Data were analysed using SPSS ver. 14 for Windows (SPSS, Chicago, Ill.), and logistic regression was used to calculate multivariate odds ratios (OR).

\section{Results}

For the 2005 survey, the mean results for all respondents and in relation to how long they used folic acid are presented in Table 1 .

\section{Knowledge}

The most recent data from 2005 showed that of the 448 respondents, 95\% $(n=425)$ had heard about folic acid and $89 \%(n=397)$ had heard about folic acid before their pregnancy (see Table 1). In total, $78 \%(n=347)$ had planned their pregnancy, while for $16 \%(n=73)$ the pregnancy was unplanned but welcomed, and for $6 \%(n=27)$ it was unplanned. Seventy-three percent $(n=328)$ knew about the protective effect of folic acid for NTDs and $32 \%(n=143)$ knew the entire advised period (4 weeks before conception to 8 weeks after). All of these aspects were related to the respondent's level of education.

Of the women who had heard about folic acid $(n=425)$, $66 \%(n=282)$ said the media were their most important source of information. Medical professionals were mentioned as a second source by 240 respondents $(57 \%)$. One specific source in the Netherlands is the pharmacist: some pharmacists put a sticker on the box of oral contraceptives advising women to take folic acid if they stop taking the pill, and this source was mentioned by $15 \%$ of the respondents $(n=62)$. Another action undertaken by pharmacists is the distribution of a leaflet on folic acid. All together, pharmacists were mentioned by $26 \%(n=110)$ of the respondents.

Use

In 2005, $80 \%(n=348)$ of respondents used folic acid at some time during the advised period, while $51 \%(n=222)$ used it during the entire advised period.

More highly educated women used folic acid significantly more often in the advised period $(63 \%)$ than less educated women $(31 \%)$ in 2005 (see Fig. 1). Other indicators for use in the advised period were parity, qualitative knowledge about folic acid, the media as a source of information and the age of the mother. Taking oral contraceptives was also a significant predictor for 
Table 1 Distribution of variables related to the use of folic acid among pregnant women in 2005

\begin{tabular}{|c|c|c|c|c|c|c|c|c|c|}
\hline \multirow[t]{2}{*}{ Variables } & \multicolumn{2}{|c|}{$\begin{array}{l}\text { Total }(n= \\
448)^{\mathrm{a}}\end{array}$} & \multicolumn{2}{|c|}{$\begin{array}{l}\text { No folic acid } \\
\text { taken }(n=87)\end{array}$} & \multicolumn{2}{|c|}{$\begin{array}{l}\text { Folic acid taken in only } \\
\text { part of advised period } \\
(n=126)\end{array}$} & \multicolumn{2}{|c|}{$\begin{array}{l}\text { Folic acid taken in } \\
\text { advised period } \\
(n=222)\end{array}$} & \multirow[t]{2}{*}{$p$ value } \\
\hline & $n$ & $\%$ & $n$ & $\%$ & $n$ & $\%$ & $n$ & $\%$ & \\
\hline Planned pregnancy & 347 & $78 \%$ & 52 & $15 \%$ & 79 & $23 \%$ & 206 & $61 \%$ & $<0.001$ \\
\hline \multicolumn{10}{|l|}{ Use of contraceptives } \\
\hline Use of oral contraceptives & 218 & $63 \%$ & 24 & $11 \%$ & 45 & $21 \%$ & 144 & $68 \%$ & 0.004 \\
\hline Use of other contraceptives & 76 & $22 \%$ & 10 & $14 \%$ & 20 & $27 \%$ & 43 & $59 \%$ & 0.64 \\
\hline \multicolumn{10}{|l|}{ Heard of folic acid } \\
\hline Not heard of it & 23 & $5 \%$ & 23 & $100 \%$ & 0 & $0 \%$ & 0 & $0 \%$ & \\
\hline During pregnancy & 28 & $6 \%$ & 10 & $38 \%$ & 16 & $62 \%$ & 0 & $0 \%$ & \\
\hline Before pregnancy & 397 & $89 \%$ & 54 & $14 \%$ & 110 & $28 \%$ & 222 & $58 \%$ & $<0.001$ \\
\hline Protective effect known & 328 & $73 \%$ & 42 & $13 \%$ & 97 & $30 \%$ & 180 & $56 \%$ & 0.17 \\
\hline Know the right period for use & 143 & $32 \%$ & 14 & $10 \%$ & 40 & $29 \%$ & 85 & $61 \%$ & 0.05 \\
\hline \multicolumn{10}{|l|}{ Sources of information } \\
\hline Media & 282 & $66 \%$ & 32 & $12 \%$ & 79 & $29 \%$ & 163 & $60 \%$ & 0.01 \\
\hline Newspapers and journals & 200 & $47 \%$ & 25 & $13 \%$ & 54 & $27 \%$ & 118 & $60 \%$ & 0.06 \\
\hline Books & 111 & $26 \%$ & 8 & $8 \%$ & 30 & $28 \%$ & 69 & $65 \%$ & 0.01 \\
\hline Internet & 109 & $26 \%$ & 8 & $8 \%$ & 37 & $35 \%$ & 62 & $58 \%$ & 0.03 \\
\hline Radio/TV & 17 & $4 \%$ & 2 & $13 \%$ & 4 & $25 \%$ & 10 & $63 \%$ & 0.78 \\
\hline Professional & 240 & $57 \%$ & 32 & $14 \%$ & 76 & $33 \%$ & 123 & $53 \%$ & 0.38 \\
\hline General Practitioner & 118 & $28 \%$ & 17 & $15 \%$ & 40 & $35 \%$ & 56 & $50 \%$ & 0.42 \\
\hline Midwife & 78 & $18 \%$ & 9 & $12 \%$ & 29 & $38 \%$ & 38 & $55 \%$ & 0.24 \\
\hline Gynaecologist & 40 & $9 \%$ & 5 & $13 \%$ & 12 & $32 \%$ & 21 & $55 \%$ & 0.91 \\
\hline Pharmacist & 110 & $26 \%$ & 15 & $14 \%$ & 29 & $27 \%$ & 63 & $59 \%$ & 0.11 \\
\hline Family & 193 & $45 \%$ & 29 & $16 \%$ & 52 & $28 \%$ & 106 & $57 \%$ & 0.51 \\
\hline \multicolumn{10}{|l|}{ Age (years) } \\
\hline$<20$ & 9 & $2 \%$ & 6 & $86 \%$ & 1 & $14 \%$ & 0 & $0 \%$ & \\
\hline $20-24$ & 48 & $11 \%$ & 15 & $32 \%$ & 15 & $32 \%$ & 17 & $36 \%$ & \\
\hline $25-29$ & 142 & $32 \%$ & 21 & $15 \%$ & 41 & $30 \%$ & 77 & $55 \%$ & \\
\hline $30-34$ & 151 & $34 \%$ & 25 & $17 \%$ & 44 & $30 \%$ & 77 & $53 \%$ & \\
\hline$>34$ & 95 & $21 \%$ & 19 & $20 \%$ & 25 & $27 \%$ & 49 & $53 \%$ & $<0.001$ \\
\hline \multicolumn{10}{|l|}{ Education level } \\
\hline Low & 76 & $17 \%$ & 29 & $40 \%$ & 21 & $29 \%$ & 22 & $31 \%$ & \\
\hline Middle & 210 & $47 \%$ & 42 & $21 \%$ & 61 & $30 \%$ & 100 & $49 \%$ & \\
\hline High & 158 & $36 \%$ & 14 & $9 \%$ & 44 & $28 \%$ & 98 & $63 \%$ & $<0.001$ \\
\hline \multicolumn{10}{|l|}{ Parity } \\
\hline No previous children & 213 & $48 \%$ & 34 & $16 \%$ & 60 & $29 \%$ & 114 & $55 \%$ & \\
\hline One previous child & 178 & $40 \%$ & 31 & $18 \%$ & 52 & $30 \%$ & 88 & $52 \%$ & \\
\hline More than one previous child & 57 & $13 \%$ & 22 & $39 \%$ & 14 & $25 \%$ & 20 & $36 \%$ & 0.003 \\
\hline Used folic acid in a previous pregnancy & 207 & $78 \%$ & 21 & $10 \%$ & 59 & $30 \%$ & 119 & $60 \%$ & $<0.001$ \\
\hline
\end{tabular}

${ }^{\text {a }}$ The total in the other three columns does not add up to 448 because of 13 missing data points

taking folic acid in the advised period $(p=0.004)$, whereas other contraceptives, such as condoms, were not. Of the women who had taken oral contraceptives before their pregnancy, $68 \%$ used folic acid in the advised period. In particular, $80 \%$ of all childless respondents who had taken oral contraceptives used folic acid in the advised period; this figure was $53 \%$ among women with one or more children $(p<0.001)$ who had used oral contraceptives.

For folic acid to be used in the advised period it is imperative the pregnancy is planned and that the woman is aware of folic acid before the pregnancy. This latter variable was found to be highly associated with the level of education (OR 22.4, 95\% CI 6.8-77.7). In the 2005 study, 321 (71.8\%) women planned their pregnancy and knew about folic acid before getting pregnant. We tested our data in a univariate approach to determine which variables were significant in terms of folic acid use as advised (see Table 1). When these variables were used in the multivariate analysis, taking folic acid in a previous pregnancy (OR 3.9, 95\% CI 1.6-9.9), use of an oral contraceptive (OR 2.1, 95\% CI 1.1-4.1) and parity (OR $0.08,95 \%$ CI: $0.01-0.5)$ were found to be the most 


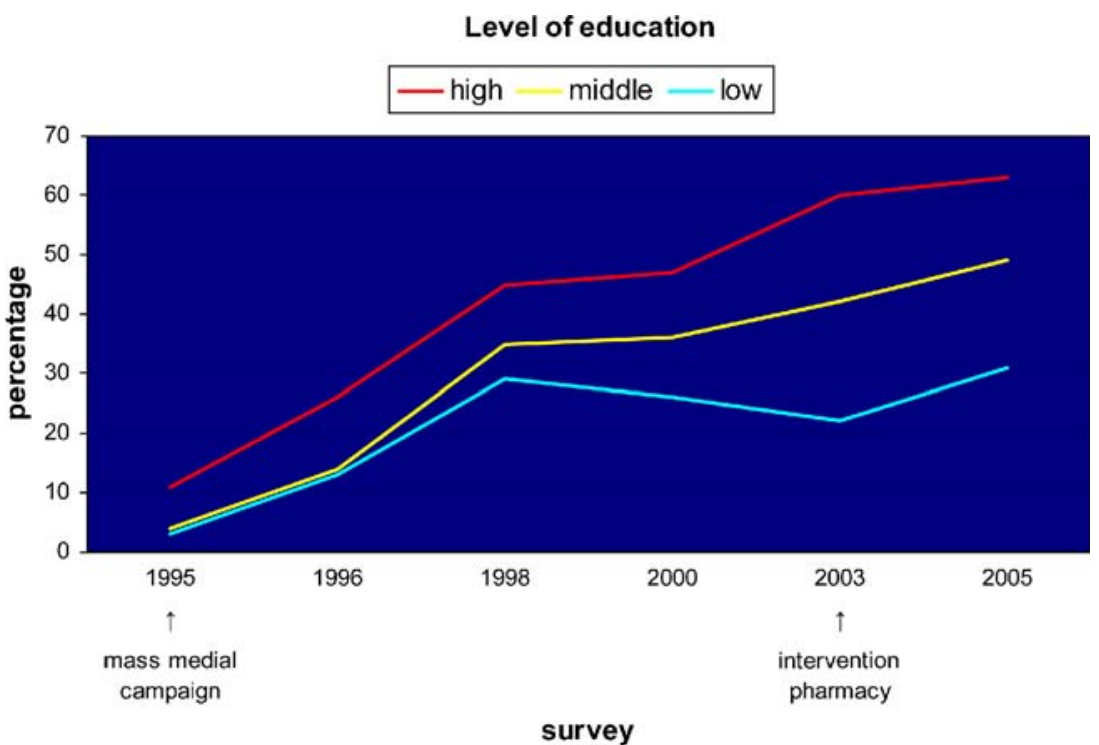

Fig. 1 Surveys in the northern Netherlands showing the use of folic acid in the advised period according to level of education, 1995-2005

important predictors for recent use. Since the use of folic acid in a previous pregnancy included by definition only multigravida, we also analysed the data for nulligravida ( $n=$ 117) under the same conditions; However, for these women, the use of oral contraceptives (OR 3.9, 95\% CI $1.2-12.4)$ proved to be the only significant factor.

\section{Discussion}

In 2005, a large majority of pregnant women in the northern Netherlands used folic acid "at some time in their pregnancy" and 51\% used it for the entire advised period. The Dutch policy of advising women who want to become pregnant to start with folic acid before conception has therefore been reasonably successful. However, based on the results of this study, there is still a great deal to be achieved in terms of public health: (1) although the majority of respondents knew about the beneficial effects of folic acid, its use in the advised period was not guaranteed, and (2) there is still a large gap between women of different educational levels in terms of folic acid use. Our data clearly reveals that the gap between women of differing educational levels with respect to their use of folic acid has been growing over the years and that this difference is due to a difference in knowledge. Once women with less education were aware of folic acid, they took it as much as women with more education.

The uptake of folic acid in the Netherlands is higher than in several other countries (see the summary by Ray et al. [11]). A Dutch survey in 1994 showed that $27 \%$ of the pregnant women were aware of the beneficial effects of folic acid, $7.8 \%$ took it at some time during the pregnancy and $0.4 \%$ took it in the recommended period [12]. The national public health campaign in 1995 resulted in an increased use of folic acid (Fig. 1). In 2005, however, a substantial proportion of women still lacked sufficient knowledge on the protective effect of folic acid and the correct period of use. This latter fact may explain why approximately $30 \%$ of the women took folic acid but only during part of the recommended period. For this group, preconceptional counselling could be an effective strategy to improve the correct use of folic acid.

A sustained effect from a one-off media campaign (like the government-sponsored folic acid campaign of 1995 in the Netherlands) cannot be expected. In contrast, proactive approaches that offer person-to-person counselling before pregnancy and provide dietary supplements to the target group have proved to be successful in China and in a physician-intervention in Arkansas (USA) [13]. Health providers, particularly gynaecologists and general practitioners, can also play an important role in informing and stimulating women planning a pregnancy to take folic acid. The role of these professionals was indeed the strongest predictor of folic acid use in an American study by De Jong-van den Berg [14]. However, in daily practice, these health providers often do not reach women before they attempt to get pregnant. Because approximately $70 \%$ of Dutch women take oral contraceptives before their first pregnancy and therefore visit their pharmacy regularly, Dutch pharmacists undertook a proactive intervention aimed at informing and motivating women taking oral contraceptives to start taking folic acid supplements before becoming pregnant. This was accomplished by means of a sticker on the oral contraceptives package, with the text "Want a baby? Ask about folic acid at your pharmacy", and by providing a brochure with more detailed information about folic acid. Our data indeed shows that among the 
women who had used oral contraceptives prior to their pregnancy, $68 \%$ had taken folic acid in the advised period and that this was not influenced by their level of education. This figure demonstrates that the information provided by the pharmacists was successful, and this study shows that the pharmacy deserves a structural place in the Dutch health care system for communicating the message of starting with folic acid before conception.

Since fortification of a staple food is not to be expected in the short term in the Netherlands, strategies to promote the taking of supplements should be developed and implemented. In a recent review, Eichholzer pleaded for creative, structural public health approaches towards preventing NTDs in countries where mandatory food fortification is not allowed [15]. We agree with this plea and conclude that is important to emphasize the distribution of knowledge on the correct period to take folic acid and to have trustworthy and well-known people as 'godmothers' of promotion campaigns. Placing the folic acid message into popular TV soap series in the Netherlands may also have a positive effect, especially on women with a lower educational level.

Our study also revealed another group worth focussing on: women with two or more children who did not use folic acid in their previous pregnancies are very unlikely to be taking folic acid in their current pregnancy. Doctors in baby clinics could play an important role in providing such information because Dutch mothers visit such a clinic an average of ten times after the birth of a child.

The aim of the Dutch Ministry of Health is to have 70\% of Dutch women wanting to become pregnant use folic acid supplements in the advised period by 2010 . This target has almost been reached among the more highly educated women (63\%), but it will take much more effort, money and creativity to increase the current level of $31 \%$ among women with a lower educational level.

Open Access This article is distributed under the terms of the Creative Commons Attribution Noncommercial License which permits any noncommercial use, distribution, and reproduction in any medium, provided the original author(s) and source are credited.

\section{Reference}

1. Lumley J, Watson L, Watson M, Bower C (2000) Periconceptional supplementation with folate and/or multivitamins for preventing neural tube defects. Cochrane Database Syst Rev (2): CD001056
2. Busby A, Abramsky L, Dolk H, Armstrong B (2005) Preventing neural tube defects in Europe: population based study. Br Med J 330(7491):574-575

3. Botto LD, Lisi A, Robert-Gnansia E, Erickson JD, Vollset SE, Mastroiacovo P, Botting B, Cocchi G, De Vigan C, de Walle H, Feijoo M, Irgens LM, McDonnell B, Merlob P, Ritvanen A, Scarano G, Siffel C, Metneki J, Stoll C, Smithells R, Goujard J (2005) International retrospective cohort study of neural tube defects in relation to folic acid recommendations: are the recommendations working? Br Med J 330(7491):571

4. Busby A, Armstrong B, Dolk H, Armstrong N, Haeusler M, Berghold A, Gillerot Y, Baguette A, Gjergja R, Barisic I, Christiansen M, Goujard J, Steinbicker V, Rosch C, McDonnell R, Scarano G, Calzolari E, Neville A, Cocchi G, Bianca S, Gatt M, Walle HD, Braz P, Latos-Bielenska A, Gener B, Portillo I, Addor MC, Abramsky L, Ritvanen A, Robert-Gnansia E, Daltveit AK, Aneren G, Olars B, Edwards G (2005) Preventing neural tube defects in Europe: a missed opportunity. Reprod Toxicol 20(3):393-402

5. Meijer, WM, De Smit, DJ, Jurgens, RA, De Jong-van den Berg, LTW (2005) Improved periconceptional use of folic acid after patient education in pharmacies: promising results of a pilot study in the Netherlands. Int J Pharm Pract 13(1):47-51, Ref Type: Generic

6. De Walle HEK, Van der Pal-de Bruin KM, De Jong-van den Berg LTW, Jeeninga W, Schouten J, De Rover C, Buitendijk SE, Cornel MC (1999) Effect of mass media campaign to reduce socioeconomic differences in women's awareness and behaviour concerning use of folic acid: cross sectional study. Br Med J 319:291-292

7. De Walle HEK, de Jong-van den Berg LTW (2002) Insufficient folic acid intake in the Netherlands: What about the future? Teratology 66(1):40-43

8. De Walle HEK, de Jong-van den Berg LTW (2007) Growing gap in folic acid intake with respect to level of education in the Netherlands. Community Genet 10(2):93-96

9. De Jong-van den Berg LTW, De Walle HEK, Van der Pal-de Bruin KM, Buitendijk SE, Cornel MC (1998) Increasing awareness of and behaviour towards periconceptional folic acid consumption in The Netherlands from 1994 to 1995. Eur J Clin Pharmacol 54:329-331

10. Van der Pal-de Bruin KM, De Walle HEK, Jeeninga W, De Rover C, Cornel MC, De Jong-van den Berg LTW, et al (2000) The Dutch "Folic Acid Campaign"-have the goals been achieved? Paediat Perinat Epidemiol 14(2):111-117

11. Ray JG, Singh G, Burrows RF (2004) Evidence for suboptimal use of periconceptional folic acid supplements globally. $\mathrm{Br} \mathrm{J}$ Obstet Gynaecol 111(5):399-408

12. de Jong-van den Berg LT, de Walle HE, van der Pal-de Bruin KM, Buitendijk SE, Cornel MC (1998) Increasing awareness of and behaviour towards periconceptional folic acid consumption in The Netherlands from 1994 to 1995. Eur J Clin Pharmacol 54(4):329-331

13. Robbins JM, Cleves MA, Collins HB, Andrews N, Smith LN, Hobbs CA (2005) Randomized trial of a physician-based intervention to increase the use of folic acid supplements among women. Am J Obstet Gynecol 192(4):1126-1132

14. de Jong-van den Berg LT, Hernandez-Diaz S, Werler MM, Louik C, Mitchell AA (2005) Trends and predictors of folic acid awareness and periconceptional use in pregnant women. Am J Obstet Gynecol 192(1):121-128

15. Eichholzer M, Tonz O, Zimmermann R (2006) Folic acid: a public-health challenge. Lancet 367(9519):1352-1361 